\title{
Macroscopic and Mesoscopic Mechanical Properties of Mine Tailings with Different Dry Densities under Different Confining Pressures
}

\author{
Zhi-jun Zhang $\mathbb{D}^{1,2,3}$ Yao-hui Guo, ${ }^{1,2,3}$ Ya-kun Tian $\mathbb{D}^{1,2,3}$ Lin Hu, ${ }^{1,2,3}$ Xi-xian Wang, ${ }^{1,2,3}$ \\ Huai-miao Zheng, ${ }^{1,2,3}$ and Ling-ling $W u(\mathbb{D})^{1,2,3}$ \\ ${ }^{1}$ School of Resource \& Environment and Safety Engineering, University of South China, 421001 Hengyang, China \\ ${ }^{2}$ Hunan Province \& Hengyang City Engineering Technology Research Center for Disaster Prediction and Control on Mining \\ Geotechnical Engineering, China \\ ${ }^{3}$ Key Discipline Laboratory for National Defense for Biotechnology in Uranium Mining and Hydrometallurgy, University of \\ South China, 421001 Hengyang, China
}

Correspondence should be addressed to Ling-ling Wu; wllshmily@foxmail.com

Received 27 June 2020; Revised 10 August 2020; Accepted 24 August 2020; Published 30 September 2020

Academic Editor: Zhengyang Song

Copyright (c) 2020 Zhi-jun Zhang et al. This is an open access article distributed under the Creative Commons Attribution License, which permits unrestricted use, distribution, and reproduction in any medium, provided the original work is properly cited.

\begin{abstract}
Particle flow numerical simulation software $\left(\mathrm{PFC}^{3 \mathrm{D}}\right)$ was utilized to establish the consolidated-undrained triaxial compression test numerical models of mine tailings with different dry densities to deeply investigate the macroscopic and microscopic characteristics of mine tailings in a tailing pond in Hunan Province. Comparing the results of the simulation and the laboratory experiment, the mesoscopic parameters of the particle flow numerical simulation were obtained through continuously adjusting the mesoscopic parameter with the higher degree of agreement between the stress-strain curve, the peak strength, and the elastic modulus as the determining standard. The macroscopic and microscopic characteristics of mine tailings were studied from the perspectives of stress-strain, axial strain-volume strain, coordination number, particle velocity vector, and contact force between particles. After numerous numerical tests, it was found that the $\mathrm{PFC}^{3 \mathrm{D}}$ simulation results are consistent with experiment results of the dry density tailing samples under different confining pressures; compared with the high confining pressure, the simulation test results at lower confining pressures were more with that of the laboratory tests; low density and high confining pressure both have inhibitory effect on the dilatancy characteristics of triaxial samples; with the same confining pressure, the dilatancy tendency of low dry density samples is suppressed comparing with the high dry density samples. The initial coordination number of the numerical model is large, which proves that the contact degree of the model is good to some extent.
\end{abstract}

\section{Introduction}

Tailings are complex geotechnical materials whose mechanical properties are greatly affected by various factors. As the main material of the tailing dam, the mechanical properties of the tailings exhibit great relevance with the safe operation of the tailing dam. Therefore, it is of great practical significance of studying the tailing mechanical properties. Under the load, the deformation of the tailing structure is mainly determined by its structural strength and modulus, while the structural strength and modulus are mainly determined by the size, shape, and arrangement of its particles, that is, the macroscopic deformation and failure of the tailing structure resulted from its fine and microstructure changes. In geotechnical and rock materials studies, many scholars at home and abroad have paid great attention on researching it from the perspective of discrete element particle flow [1-4]. The relationship between mesoparameters and macroparameters in discrete-element particle flow simulation has always been a difficult point. Cui et al. [5] embedded the mode search method in the least square method to automatically calibrate the mesoparameters of the discrete element numerical test 
of the biaxial compression of sand materials. Iterative calibration method was utilized by $\mathrm{Xu}$ and Sun [6] to calibrate the mesoparameters of the sand, and compared with the laboratory test results, it was found that it can reduce many unnecessary and repeated test parameter work. In rock materials, discrete element method was utilized by some scholars to perform PFC numerical simulation [3, 4]. Liu et al. [7] established a parallel bonding model for uniaxial and biaxial numerical simulations of rock materials through $\mathrm{PFC}^{2 \mathrm{D}}$ and studied the effect of the change of mesoparameters on the strength of the specimen under the parallel bonding model. A series of PFC numerical experiments were conducted by Yang and Han [8] to explore the effects of particle friction coefficient, normal stiffness, tangential stiffness, and the bonding strength between particles in particle clusters on the macroscopic mechanical properties of rockfill materials. The particle flow discrete element has also been widely used in geotechnical materials, and $\mathrm{Xu}$ [9] had performed the secondary development of PFC $^{2 \mathrm{D}}$ software. He bundled the basic particles belonging to the same particle to obtain a sample that can be crushed and carried out many direct shear simulation tests. It was found that the degree of particle crushing exhibited influence on the shear expansion characteristics of coarsegrained soil and the internal friction angle. Luo et al. [10] used Chengde medium-density sand as the basic research object to simulate the sliding condition between particles with the contact friction sliding model and studied how the porosity and the internal friction angle between the particles influence on the mechanical properties of sand. By comparing the numerical simulation results of particle flow between transparent sand and standard sand, $\mathrm{Li}$ [11] supposed that transparent sand that can replace natural sand for indoor testing is reasonable under certain conditions. Zhou and Chi [12] explained the assumptions and basic principles of particle flow using $\mathrm{PFC}^{2 \mathrm{D}}$ to numerically simulate the sand biaxial test, and their results showed that the particle flow numerical simulation test can effectively simulate the formation and development of sand shear bands mechanism. Shen et al. [13] conducted particle flow biaxial compression tests on loose sand and dense sand to explore the macroscopic parameter response corresponding to the changes in mesoscopic parameters by adjusting the size of mesoscopic parameters such as particle contact stiffness and internal friction coefficient. Yin et al. [14] conducted a PFC uniaxial compression test on geotechnical materials under different particle size conditions, showing that the numerical simulation of geotechnical materials has certain stability when the internal scale ratio is less than 0.01 . Yang and $\mathrm{Li}[15]$ used the $\mathrm{PFC}^{3 \mathrm{D}}$ particle flow program to numerically simulate the direct shear test of sand under different vertical pressures and explain the phenomenon of sand dilatation at a mesoscopic point of view. Based on the spherical particles in PFC, Yang and $\mathrm{Li}$ [16] introduced a rigid clump unit composed of pebble to establish dumbbell-shaped and elliptical cluster particles and found that the elliptical particles exhibited higher relevance with the simulation results. Based on the results of the laboratory triaxial test, Geng et al. [17] utilized PFC software to carry out the numerical simulation of the particle flow of coarse-grained soil and found that the shape of the particle has a significant effect on the shear strength of the material. Wang et al. [18] used $\mathrm{PFC}^{2 \mathrm{D}}$ to study the size effect of the large triaxial sample, suggesting that scaling the sample by the equal mass substitution method was finite but could not be infinitely reduced. Yin et al. [19] conducted particle flow simulation tests on sand through $\mathrm{PFC}^{2 \mathrm{D}}$ and found that the friction angle between the sand and that between the particles could be approximated as an inclined line, and the cohesive force and the contact strength of the particles obeyed the linear law as well approximately.

There are relatively numerous researches about sandy soil, coarse grained soil, and rock materials, but few studies on tailings. In addition, the nonbonded linear contact model is used in most of above studies, and some are exploring through the direct shear test. Compared with the triaxial test, the direct shear test artificially defines the location of the shear failure surface, while that of triaxial test shear is along the weakest surface of the specimen. Based on the laboratory triaxial test results of tailings specimen, this paper compares the simulation results with the laboratory test results, and by continuously adjusting the parameters with the higher degree of agreement between the stress-strain curve, the peak strength, and the elastic modulus as the determining standard. The microstructure characteristics of tailings were analyzed from the perspective of coordination number, particle velocity vector, and particle displacement field. The method obtains parameters that are not easily obtained in laboratory tests.

\section{Materials and Method}

The tailings used in this test were taken from a tailing pond in Hengyang, Hunan Province, and the grading parameters of the samples obtained by sieving are shown in Table 1. Coefficient of nonuniformity $C_{\mathrm{u}}$ is 2.5320; coefficient of curvature $\mathrm{C}_{c}$ is 1.6610. As $C_{\mathrm{u}} \geq 5$ and $C_{\mathrm{c}}=1 \sim 3$ cannot be satisfied at the same time, the tailing grading is not good. These samples were dried to a constant weight and then cooled down to room temperature to make compact samples with a diameter of $39.1 \mathrm{~mm}$ and a height of $80 \mathrm{~mm}$. All samples were prepared using self-made triaxial device of acrylic tube. The device is composed of two semicircular cylinders of specified size. The correspondence between the number of compactions and the dry density was determined by a large amount of tests. The specific dry density sample was obtained by controlling the number of compactions with compacting in four layers. The samples before and during the triaxial test are shown in Figure 1.

LH-TTS series automatic triaxial apparatus were employed with the maximum axial loading force of $10 \mathrm{kN}$ at the loading rate ranging between 0.0001 and $4.8 \mathrm{~mm} / \mathrm{min}$. The process of triaxial loading is controlled by a computer, and the axial strain of the sample reaches $15 \%$ as the termination condition of loading. The consolidated-undrained triaxial compression test was carried out for each specific dry density sample with the loading rate of $0.6 \mathrm{~mm} / \mathrm{min}$ at a confining pressure of $100 \mathrm{kPa}, 200 \mathrm{kPa}$, and $300 \mathrm{kPa}$, respectively. The test data was automatically collected and collated by the computer, and Figure 2 is the picture of the automatic triaxial apparatus. 
TABle 1: Particle composition parameters of tailings.

\begin{tabular}{lcccc}
\hline $\begin{array}{l}\text { Effective diameter } \\
\left(d_{10} / \mathrm{mm}\right)\end{array}$ & $\begin{array}{c}\text { Median size } \\
\left(d_{30} / \mathrm{mm}\right)\end{array}$ & $\begin{array}{c}\text { Particle composition parameters } \\
\text { Constrained size } \\
\left(d_{60} / \mathrm{mm}\right)\end{array}$ & $\begin{array}{c}\text { Coefficient of } \\
\text { nonuniformity }\left(C_{\mathrm{u}}\right)\end{array}$ & $\begin{array}{c}\text { Coefficient of } \\
\text { curvature }\left(C_{\mathrm{c}}\right)\end{array}$ \\
\hline 0.0780 & 0.1620 & 0.2000 & 2.5320 & 1.6610 \\
\hline
\end{tabular}

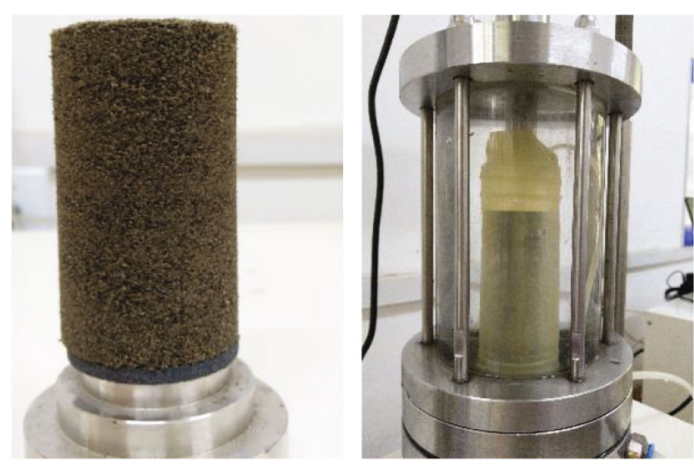

FIGURE 1: Samples before and during loading.

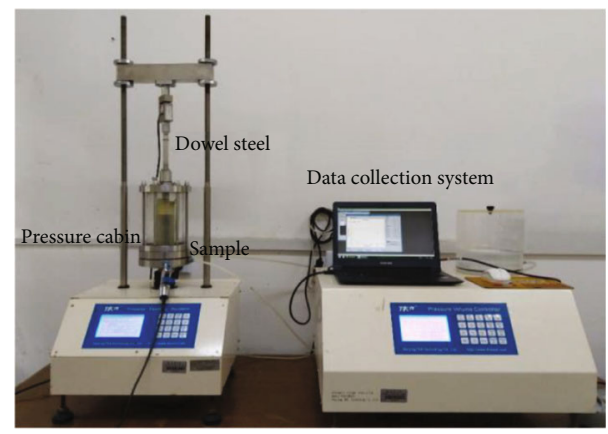

Figure 2: Automatic triaxial apparatus

\section{Experimental Results and Analysis}

Excess pore water pressure has been the main cause of many engineering accidents. The increase of excess pore water pressure would lead to the decrease of the equivalent axial and radial effective principal stresses as well as the diameter of the Mohr circle to be unchanged and shifting to the left, causing soil instability and destruction [20]. The value of the excess pore water pressure corresponding to each axial strain can be obtained directly from the triaxial consolidated-undrained test. Figure 3 shows the relationship between pore water pressure and axial strain under different confining pressures (only the excess pore water pressure is involved in this paper).

From Figures 3(a) to 3(c), the pore water pressure of each dry density tailing sample under different confining pressures exhibited the trend of increasing and then decreasing as the axial strain increased. The pore water pressure can reflect the shear expansion and contraction characteristics of the specimen during triaxial compression [21]. When the confining pressure is the same, the larger dry density, the larger peak pore water pressure; and the larger dry density sample is more likely to be negative, causing the development of sample dilatancy characteristic. When the dry density is the same, the larger confining pressure is, the larger pore water pressure corresponds to each axial strain, suppressing the negative value of the pore water pressure. Hence, the occurrence of sample dilatation was limited by the high confining pressure. When the density is $1.61 \mathrm{~g} / \mathrm{cm}^{3}$ and $1.66 \mathrm{~g} / \mathrm{cm}^{3}$, dilatancy happened on all the samples with confining pressure of $100 \mathrm{kPa}$ (limited to space, the relationship between stress and strain in the laboratory test was not discussed separately).

\section{Particle Flow Model}

4.1. Particle Size and Model Size. If the model is generated according to the original gradation of the sample, millions of spherical particles will be required. In order to avoid generating more particles when generating the numerical model of the triaxial test, resulting in longer calculation time, the original gradation of the sample cannot be used directly. Ning [22] found in the triaxial particle flow test of cohesive soil that the effect of particle size on the macroscopic strength characteristics of the soil is much smaller than the friction coefficient and bond strength between the particles, and when $D / R \geq 20$, the effect on the strength parameters of the soil is almost negligible ( $D$ is the model diameter; $R$ is the maximum particle size). Combined with the size of the laboratory triaxial test sample and the distribution of the particle gradation of the tailings itself, the size of the triaxial particle flow model is the same as the laboratory test size, and the particle size is uniformly distributed between $0.85 \mathrm{~mm}$ and $1.41 \mathrm{~mm}$.

4.2. Contact Model. In the simulation test of the particle flow of sandy soil, the contact method chosen by most researchers is the nonbonded contact [10-12]. Considering that the tailing material itself has bonding characteristics, it is more reasonable to select a linear contact bond model. Linear contact bond model is generally composed of linear group, damping group, and bonding group. Within the range of the target gap, the bonding force between the particles can be generated but the moment cannot be resisted. Between the particles, there can be no coexistence between bonding and sliding. It is assumed that there are two springs at the bond between the particles to provide a constant normal, tangential stiffness and specific tensile and shear strength [23]. If the normal tensile force is greater than the tensile strength, the bond will break, and the normal and tangential bonding will disappear; if the tangential shear force is greater than the tangential bond strength, the bond will fail, but the contact is subjected to normal pressure and the tangential shear force. The force at the contact will not change if it is less than the product of normal pressure and particle friction coefficient. Figure 4 shows a linear contact bond model. 


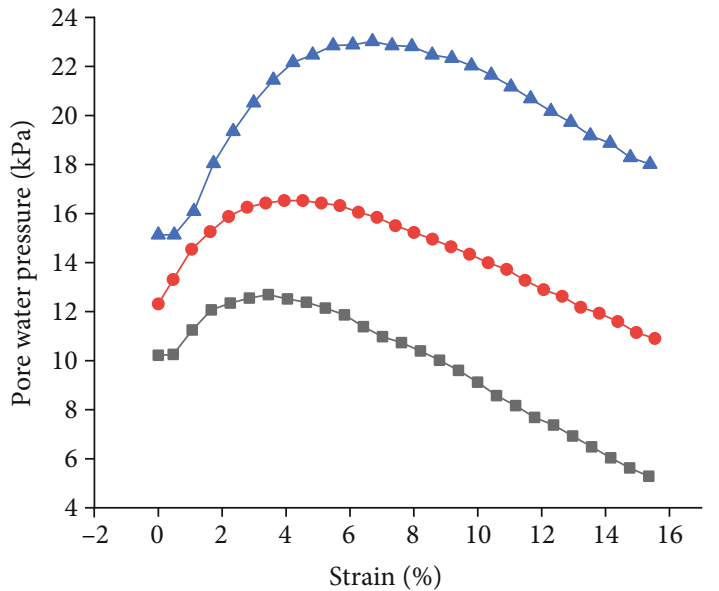

(a) Dry density is $1.53 \mathrm{~g} / \mathrm{cm}^{3}$

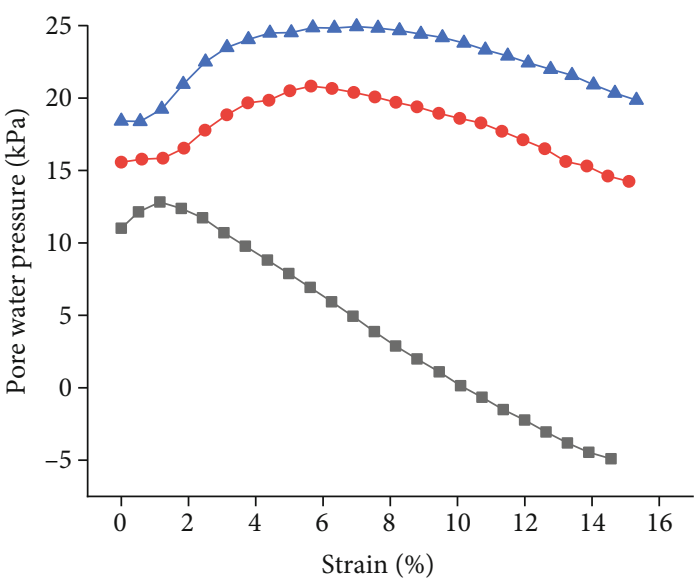

(b) Dry density is $1.61 \mathrm{~g} / \mathrm{cm}^{3}$

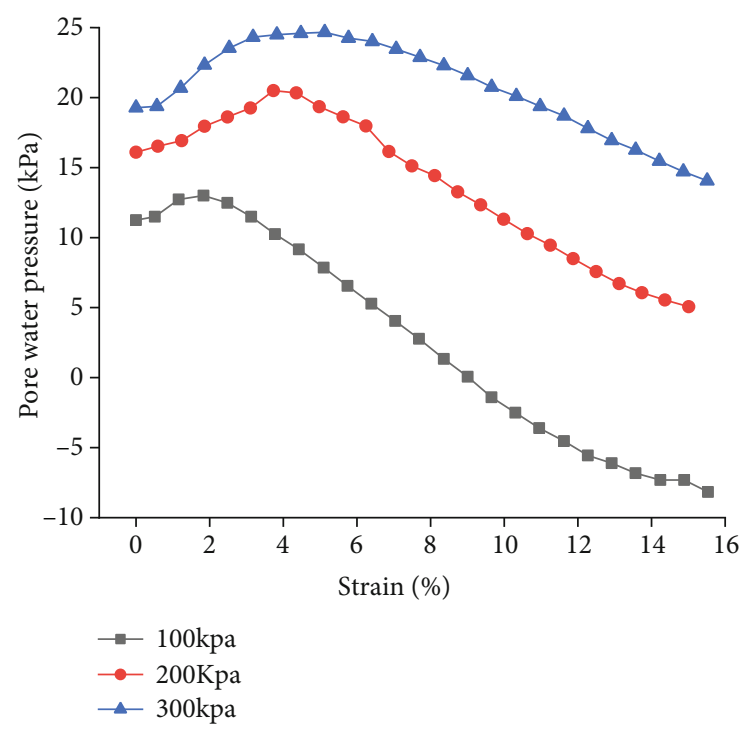

(c) Dry density is $1.66 \mathrm{~g} / \mathrm{cm}^{3}$

FIGURE 3: Relationship between pore water pressure and axial strain.

Dashpot force $\left(\mathrm{F}^{\mathrm{d}}\right)$, not shown. Linear force $\left(\mathrm{F}^{1}\right)$, linear elastic \& either bonded or frictional.

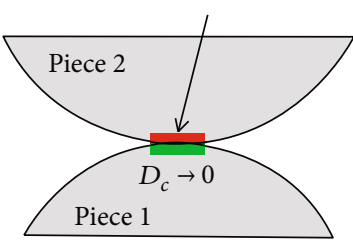

$\mathrm{F}_{\mathrm{c}}=\mathrm{F}^{1}+\mathrm{F}^{\mathrm{d}}, \mathrm{M}_{\mathrm{c}} \equiv 0$

\section{Bonded}

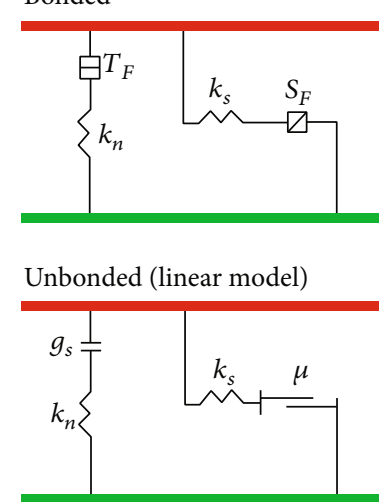

FIGURE 4: Linear contact bond model (from PFC5.0). $\mathbf{F}_{\mathbf{c}}$ is contact force. $D_{c}$ is distance between of particles. $\mathbf{M}_{\mathbf{c}}$ is contact moment. $T_{F}$ is tensile force. $S_{F}$ is shear force. $g_{s}$ is specific gap. $k_{n}$ is normal stiffness. $k_{s}$ is shear stiffness. $\mu$ is friction coefficient.
4.3. Model Establishment. According to the determined model size and particle size, linear bonding contact was set between the spherical particles, and the cylinder command was utilized to generate the uncovered cylindrical side wall of the particle flow triaxial test model. To reduce the calculation time of wall generation, the plane command was utilized to create a plane rigid wall at the top and bottom of the specimen. To ensure the uniformity of the generated model, the friction coefficient of the wall is 0 [24]. In the laboratory test, the flexible restraint was provided by the rubber jacket on the side wall of the sample, hence setting the wall of the uncovered cylindrical side wall as a flexible wall. Due to the lateral deformation of the sample under the force during the loading phase, the length of each side of the plane rigid wall is set to twice the diameter of the model to prevent some particles from exceeding the wall. The PFC particle flow numerical simulation is shown in Figure 5.

4.4. Confining Pressure Servo and Loading System. During the PFC simulation process, the confining pressure is provided 


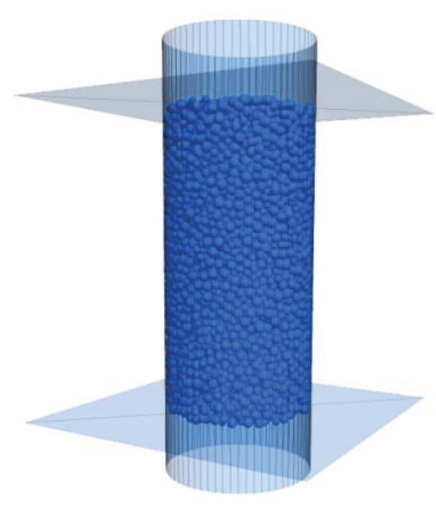

Figure 5: Model of the particle flow numerical simulation.

by the top and bottom plane rigid walls and the flexible wall with uncover cylindrical side wall in the initial consolidation stage before loading; the confining pressure is only provided by the flexible uncovered cylindrical side wall during the loading stage. The confining pressure and the axial pressure were adjusted by controlling the movement speed of the cylindrical side flexible wall and the plane rigid wall, respectively. The magnitude of the force is obtained by formula (1). Setting the target strain value to reach the target strain value as the loading stop condition, the top and bottom rigid planes move slowly at the same time to load the sample [25].

$$
\Delta F^{W}=K_{n}^{w} N_{c} u^{w} \Delta t
$$

where $\Delta F^{W}$ is confining or axial pressure. $K_{n}^{w}$ is the average normal stiffness of particles in contact with the wall. $u^{w}$ is the wall velocity. $N_{c}$ is the number of particles in contact with the wall. $\Delta t$ is time step.

4.5. Calibration of Mesomechanical Parameters. Calibration of mesomechanical parameters has always been an important issue in PFC simulation because there is no specific relationship between the mesoscopic parameters and the macroscopic parameters. Based on the calibration of mesoscopic parameters in recent studies, the parameters are continuously adjusted by trial and error until the stress-strain curve, elastic modulus, peak strength, and laboratory test results are approximately the same [26]. The detailed simulation parameters are shown in Table 2.

\section{PFC Numerical Simulation Results and Analysis}

5.1. The Relationship Curve of Stress-Strain. From Figures 6(a) to 6(c), the stress-strain curve, peak strength, and elastic modulus of the numerical simulation of each dry density tailing sample and laboratory tests under different confining pressures were basically consistent. With the increase of the dry density, the peak strength of the samples with the same confining pressure increased significantly. With the increase of confining pressure, the simulation curves at each dry density showed that the degree of strain softening to strain softening was suppressed and finally strain hardening occurred. That could be explained that as the confining pres- sure increased, the sliding and turning of the particles in the simulation were restricted to enhance the load-bearing capacity, and the sample strain hardening phenomenon occurred macroscopically. At the same time, as the confining pressure increased, the axial strain corresponding to the peak stress in the simulation curve also tended to increase. In the simulation curve, the peak stress of each dry density tailings increased with the increase of confining pressure and showed a nearly linear relationship consistent with the conclusion that the peak strength and the confining pressure exhibited linear relationship [18]. Figure 7 showed the relationship between peak strength and confining pressure. When the confining pressure was $100 \mathrm{kPa}$ and $200 \mathrm{kPa}$, the stressstrain curve of PFC simulation and laboratory test were in excellent relevance; but when the confining pressure was $300 \mathrm{kPa}$, the curve matched poorly. This was mainly because the larger particles in the tailings sample were more likely to be crushed when compressed under high confining pressure, but the PFC numerical simulation model assumes that the ball particles are rigid, so the matching degree between laboratory tests and PFC numerical results under high confining pressures is poor. It can be seen from Figure 6 that the initial elastic modulus of the simulation curve was slightly smaller than the laboratory test due to the large crushed particles in the real sample, but the particles in the numerical simulation cannot be crushed. In the numerical experiment, different dry densities were achieved by controlling the change of porosity while keeping other simulation parameters unchanged. The peak strength decreases by $46.7 \mathrm{kPa}$ when the porosity increases from 0.32 to 0.45 at the confining pressure of $100 \mathrm{kPa}$; the peak strength decreases by $213.3 \mathrm{kPa}$ and 317.7 when the porosity increases from 0.32 to $0.45 \mathrm{kPa}$ at the confining pressure of $200 \mathrm{kPa}$ and $300 \mathrm{kPa}$. The stress-strain curves of the numerical test showed strain hardening before the deviatoric stress reached the peak value, and the volume change showed a shear shrinkage characteristic. The stress-strain curve of the numerical test before the deviatoric stress reached the peak shows strain hardening, and the volume change became the shrinkage characteristic. After the peak stress was reached, the volume change showed the tendency of shear expansion, which was consistent with the laboratory test results in Figure 3. From a mesoscopic point of view, as the loading progresses gradually, the pores in the sample are continuously compressed, the particle spacing decreases, the number of contact points increases, and the body shrinkage characteristics appear macroscopically before the peak stress is reached; after the deviatoric stress reaching the peak stress, the bite force between the particles reached the peak due to the maximum restriction and restraint effect between the particles at the peak stress; therefore, as further loading destroyed the bite between the particles, the particles began to slip and rotate, with the tendency to expand radially. The mutual restriction between particles and the deviatoric stress decreased, and the volume of the sample began to expand, and the macroscopic performance is the dilatancy characteristic.

5.2. Volumetric Strain-Axial Strain Relationship. The volume strain of the tailing sample is the amount of change per unit volume of the sample. Based on the initial volume, volume 
TABLe 2: Particle flow simulation parameters.

\begin{tabular}{lccccc}
\hline Radius $(R / \mathrm{mm})$ & $\begin{array}{c}\text { Radius ratio } \\
\left(R_{\mathrm{Max}} / R_{\mathrm{Min}}\right)\end{array}$ & Friction coefficient $(\mu)$ & $\begin{array}{c}\text { Normal stiffness } \\
\left(k_{\mathrm{n}} /(\mathrm{kN} / \mathrm{m})\right)\end{array}$ & $\begin{array}{c}\text { Normal-to-shear stiffness } \\
\text { ratio }\left(k_{\mathrm{n}} / k_{\mathrm{s})}\right.\end{array}$ & $\begin{array}{c}\text { Tensile strength } \\
\left(T_{\mathrm{F}} / \mathrm{KN}\right)\end{array}$ \\
\hline $85-141$ & 1.66 & 0.5 & 60 & 1.33 \\
\hline
\end{tabular}

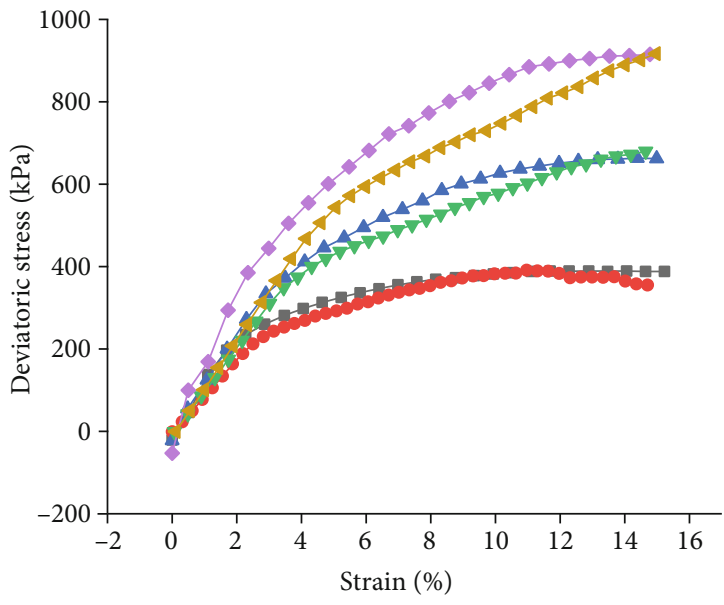

(a) Dry density is $153 \mathrm{~g} / \mathrm{cm}^{3}$

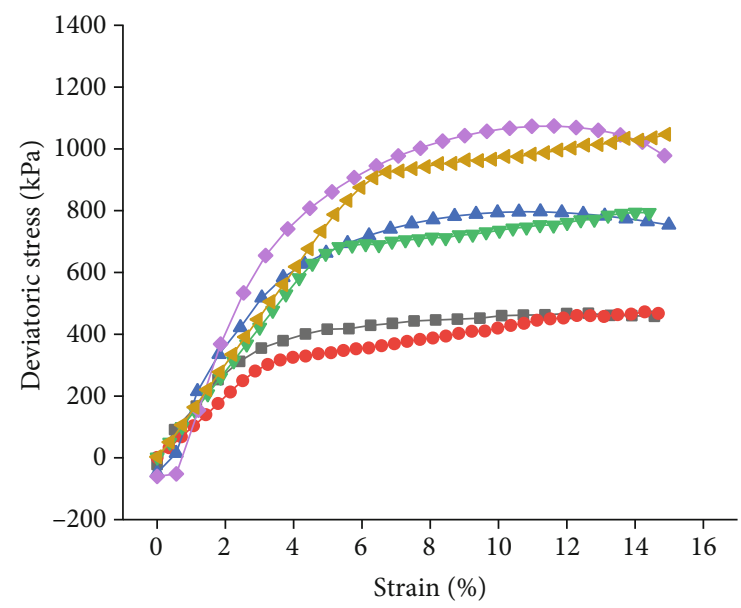

(b) Dry density is $1.61 \mathrm{~g} / \mathrm{cm}^{3}$

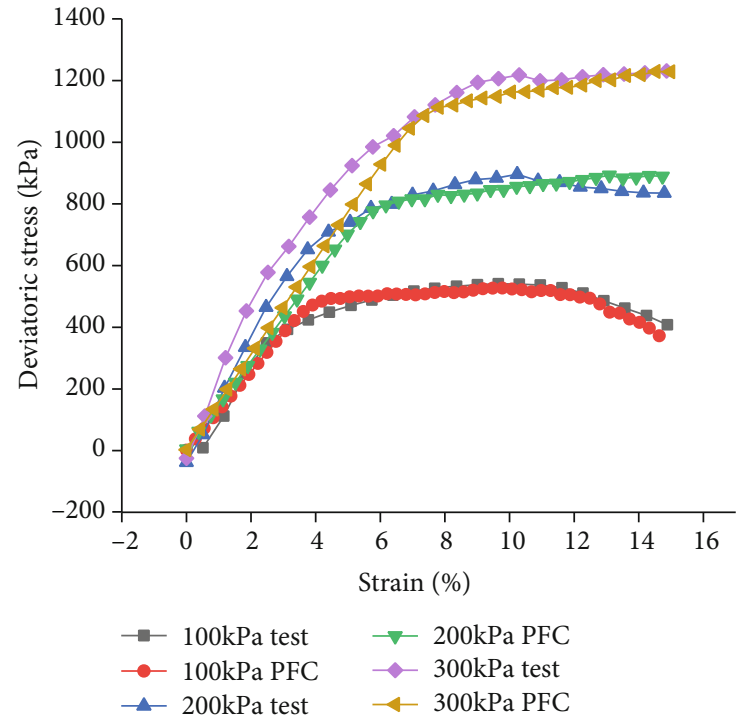

(c) Dry density is $1.66 \mathrm{~g} / \mathrm{cm}^{3}$

Figure 6: Stress-strain curves of laboratory tests and PFC simulation.

compression serves as positive volume strain, volume expansion serves as negative volume strain, and the point where the slope of the axial strain and volume strain curve of is 0 is defined as the critical point of the shear expansion trend. The relationship between axial strain and volume strain under PFC numerical simulation is shown in Figure 8.

In the PFC simulation, there is no dilatancy phenomenon on the sample with a confining pressure of $100 \mathrm{kPa}$ and a dry density of $1.61 \mathrm{~g} / \mathrm{cm}^{3}$, which is not consistent with the result of a slight dilatation phenomenon in Figure 3. This is that the particle flow simulation assumed that the particles are rigid bodies, and the particles in the laboratory test can be crushed and deformed. The crushed and deformed particles are recombined and replaced into the large pores in the sample, resulting in the number of large pores reduced, and the degree of crushing and deformation is greater under high confining pressure. Unlike laboratory tests, the dominant factor in the change of sample volume in PFC numerical simulation is the rearrangement between particles due to the sliding and squeezing between particles. It can be clearly seen from Figures 8(a) to 8(c) that there is a big difference in the relationship between the volume strain-axial strain curves of different confining pressure simulations at the same dry density. The sample at the confining pressure of $100 \mathrm{kPa}$ with lower dry density has a more obvious dilatancy trend, but no dilatation occurs compared with the initial sample volume; as the 


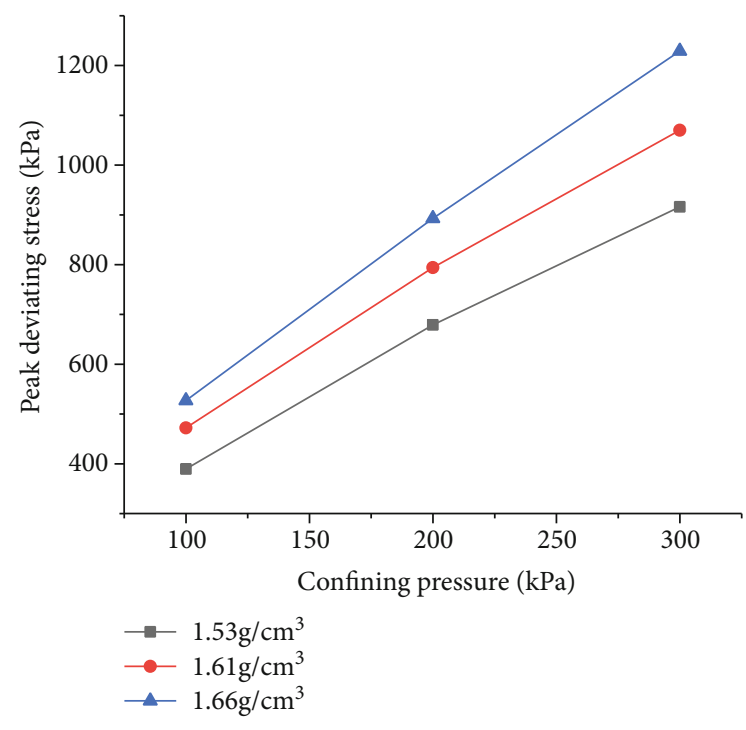

Figure 7: The relation curve between peak strength and confining pressure in PFC test

confining pressure increases, the critical point of the dilatation trend that corresponds to the axial strain becomes larger; there is no obvious tendency of shear expansion when the axial strain reaches $15 \%$ at the confining pressure of $300 \mathrm{kPa}$. This is because, for samples with a low dry density at small confining pressure, the lateral restraint force is small, and when loaded to a certain degree, the sample expanded radially due to the slippage and rotation between the particles. When the confining pressure is larger, the larger lateral binding force enables to compress to a greater degree due to the larger porosity of the sample itself, showing the axial strain corresponding to the critical point of the shear dilatancy trend increases. Compared with the low dry density sample, the larger dry density has a certain promoting effect on the sample's dilatancy trend at the same confining pressure. This can be explained as, when the density is higher, the porosity is lower, and the gap between the particles is smaller. After the load increases to a certain degree, the particles in the sample slide and renew arrangement under the combined action of axial pressure and confining pressure, resulting in particles from a tightly arranged state to a relatively loose degree, which is more prone to more obvious radial expansion; the particles with a small dry density are loosely arranged, and the particles squeeze, slide, and rotate against each other under load by filling some large pores; the sample had a higher degree of compression, and the macroscopically showed that the dilatancy characteristic was suppressed. High confining pressure and low density exhibited inhibitory effect on the dilatancy characteristics of the sample. The volume strain shows a negative value, which shows the phenomenon of shear dilatation macroscopically with the confining pressure of $100 \mathrm{kPa}$ at dry density of $1.66 \mathrm{~g} / \mathrm{cm}^{3}$.

5.3. Coordination Number Changes during Loading. Coordination number is an extremely important index in particle flow simulation, which is used to evaluate the degree of good contact between particles and compactness of a particle system. In this paper, the coordination number in the loading process is monitored by setting a measuring ball with a radius of $17 \mathrm{~mm}$ at the center of the model, as shown in Figure 9. The coordination number $C_{n}$ is obtained by formula (2), and the coordination number changes of different dry density models in the loading process are shown in Figure 10 (coordination number, particle velocity vector, and contact force between particles were all obtained at a confining pressure of $100 \mathrm{kPa}$ ).

$$
C_{\mathrm{n}}=\frac{2 N_{\mathrm{c}}}{N_{\mathrm{b}}}
$$

where $C_{\mathrm{n}}$ is coordination number. $N_{\mathrm{c}}$ is actual number of contacts. $N_{\mathrm{b}}$ is total particles number.

When the confining pressure was $100 \mathrm{kPa}$, the change of coordination number of different dry density models during loading showed that the initial coordination number of each dry density model was large, indicating good contact between particles in each model. With the loading process continued, the coordination numbers of different dry density models showed a trend of first increasing and then decreasing, and in the whole loading process, the coordination numbers of models with higher dry density were larger than those with lower dry density. When the dry density was $1.66 \mathrm{~g} / \mathrm{cm}^{3}$, the coordination number of the models decreased greatly at the later stage of loading, which may be because the samples with high dry density and low confining pressure were more prone to dilatation. The radial expansion of the model reduced the numbers of contact between particles, and the coordination number decreased significantly.

5.4. Velocity Vector Diagram between Particles. When the confining pressure is $100 \mathrm{kPa}$, the velocity vector diagram corresponding to different axial strains in the loading process is shown in Figure 11. By observing the particle velocity vector field corresponding to each axial strain of the model under different densities, it was found that when the axial strain was $5 \%$, the particle velocity directions in the model with different dry densities were more orderly. Due to the loading mode of upper and lower loading plates moving slowly at the same time is adopted in the model, when the axial strain is small, the particles in the upper part of the model show a downward movement trend as a whole, while the particles in the lower part of the model show an upward movement trend. Therefore, the particle movement direction is more orderly. With the increase of axial strain, the movement tendency of particles becomes disordered. When the axial strain is $10 \%$ or $15 \%$, the particles near the side wall of the model with different dry densities show a trend of radial horizontal outward motion, which indicates that the model has shown a trend of dilatancy at this time, which is consistent with the phenomenon in Figure 8. Compared with the low dry density model, when the axial strain is the same, the particle velocity field of the high dry density model has a higher degree of disorder and the radial horizontal movement of the particles near the side wall is more obvious. It is proved from the microscopic point of view that the high dry density has a certain promotion effect on the dilatancy 


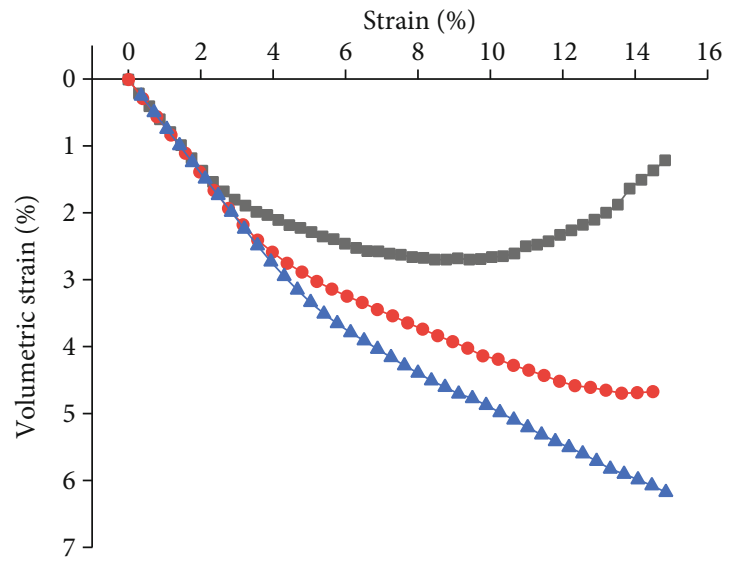

(a) Dry density is $1.53 \mathrm{~g} / \mathrm{cm}^{3}$

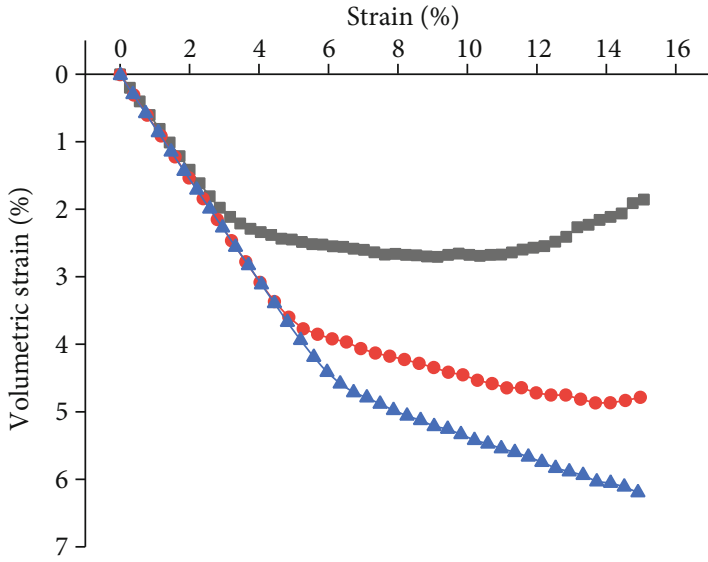

(b) Dry density is $1.61 \mathrm{~g} / \mathrm{cm}^{3}$

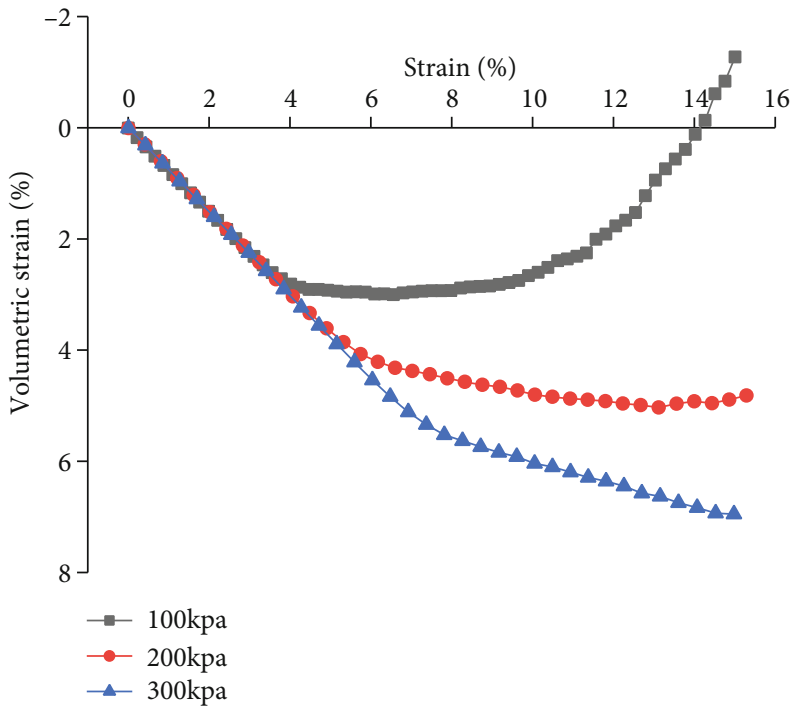

(c) Dry density is $1.66 \mathrm{~g} / \mathrm{cm}^{3}$

FiguRE 8: The relation curve of axial strain and volume strain in PFC numerical simulation.

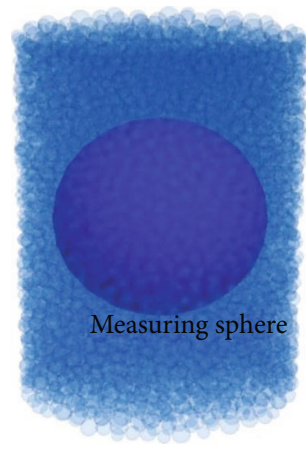

Figure 9: Measuring ball diagram.

of the sample. It is corresponding to the conclusion in Section 5.2 that the sample shows dilatancy with $100 \mathrm{kPa}$ confining pressure and $1.66 \mathrm{~g} / \mathrm{cm}^{3}$ dry density.

5.5. Contact Force between Particles. When the confining pressure is $100 \mathrm{kPa}$, the contact force between particles corresponding to different axial strains in the loading process is

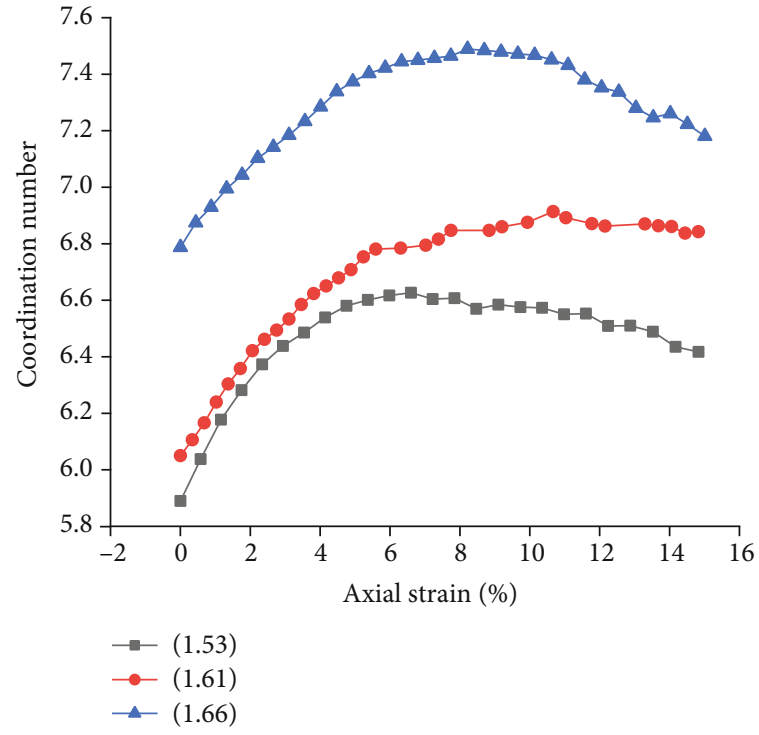

FIgURe 10: Coordination number changes of different dry density models during loading. 


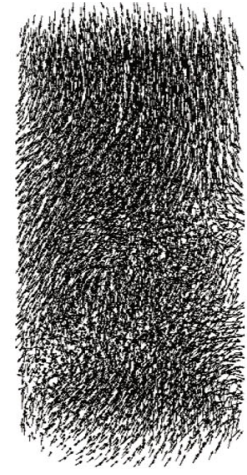

Axial strain 5\%

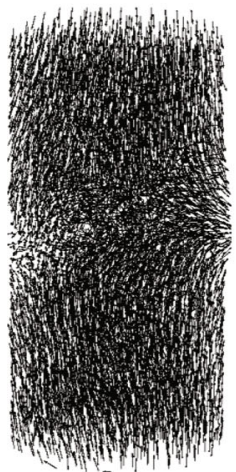

Axial strain 5\%

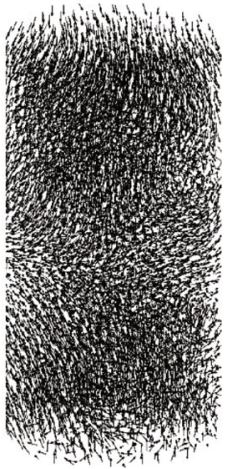

Axial strain 5\%

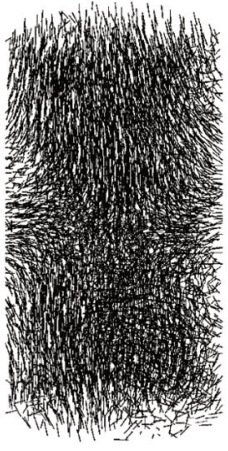

Axial strain 10\%

Dry density $1.53 \mathrm{~g} / \mathrm{cm}^{3}$

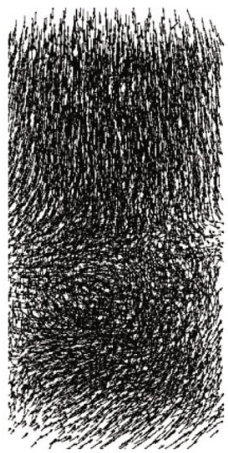

Axial strain $10 \%$

Dry density $1.61 \mathrm{~g} / \mathrm{cm}^{3}$

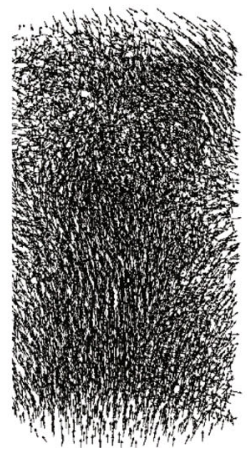

Axial strain 10\%

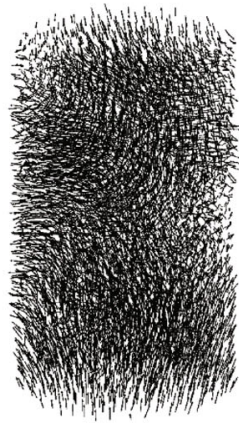

Axial strain 15\%

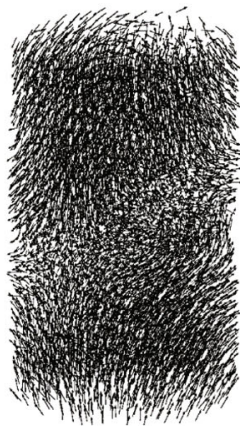

Axial strain 15\%

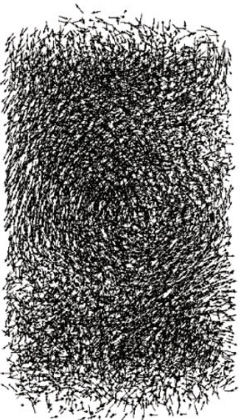

Axial strain 15\%

Dry density $1.66 \mathrm{~g} / \mathrm{cm}^{3}$

FIGURE 11: Velocity vector diagram of various axial strain sample under different dry density.

shown in Figure 12. The thicker the black line, the greater the contact force. By observing the contact force corresponding to each axial strain of the models under different dry densities, it is found that the magnitude of contact force between particles is smaller and more homogeneous in the consolidation stage when the axial strain is 0 . With the continuation of the loading procedure, the homogenization of the magnitude of contact force between particles with different dry density models presented a trend of first decreasing and then increasing. When the axial strain was large, the magnitude of contact force between particles also developed toward homogenization. With the increase of axial strain, the contact force between the particles and the upper and lower loading plates increased significantly, and the contact force of the core area connecting the upper and lower loading plates in the middle of the model also increases obviously. When the axial strain is $10 \%$ or $15 \%$, the core area of the models bears most of the axial pressure. When the dry density was $1.66 \mathrm{~g} / \mathrm{cm}^{3}$ and the axial strain was $15 \%$, the particle contact force within a certain range near the side wall of the model decreased significantly, which may 


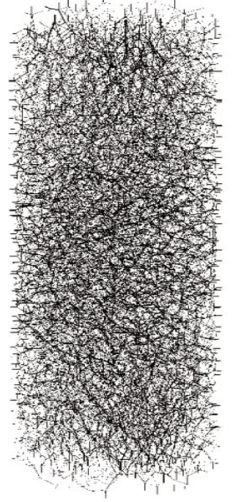

Axial strain 0

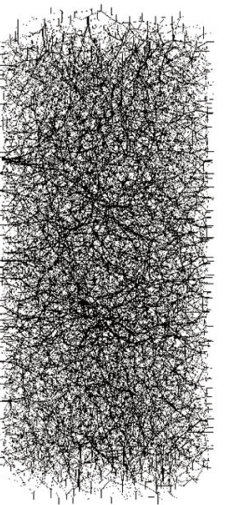

Axial strain 0

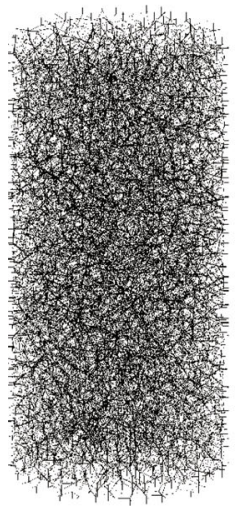

Axial strain 0

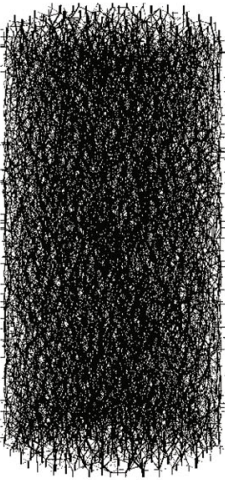

Axial strain 5\%

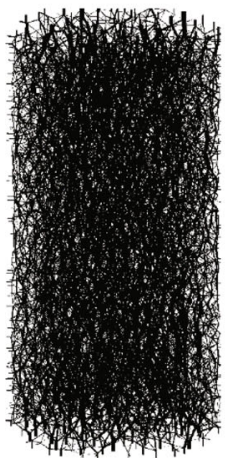

Axial strain $10 \%$

Dry density $1.53 \mathrm{~g} / \mathrm{cm}^{3}$
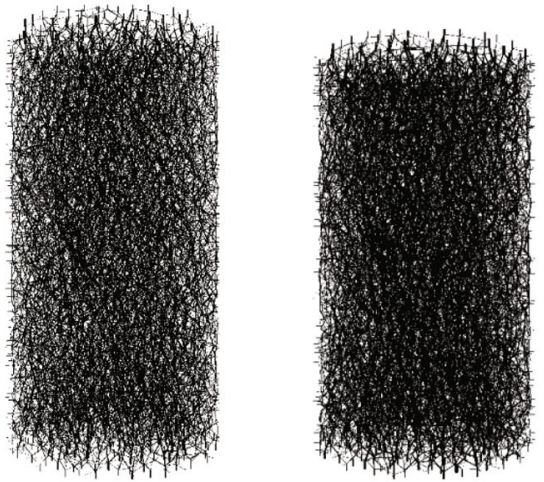

Axial strain $10 \%$

Dry density $1.61 \mathrm{~g} / \mathrm{cm}^{3}$

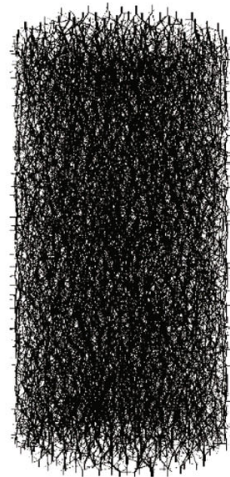

Axial strain 5\%

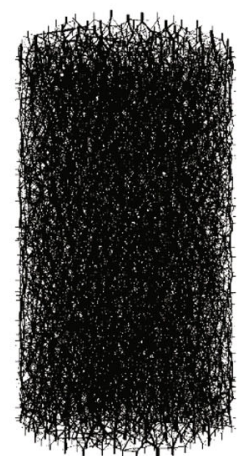

Axial strain $10 \%$

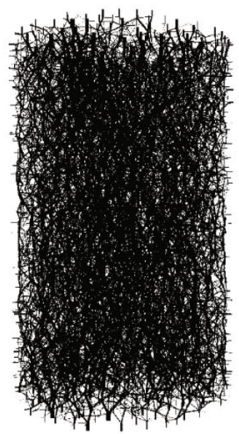

Axial strain $15 \%$

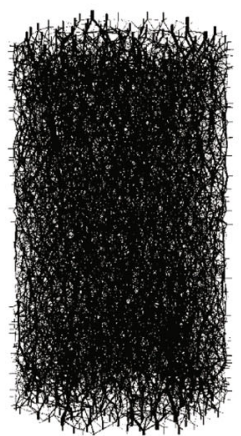

Axial strain $15 \%$

Dry density $1.66 \mathrm{~g} / \mathrm{cm}^{3}$

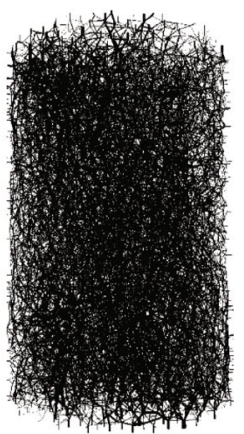

Axial strain 15\%

FIGURE 12: Contact forces between particles of axial strain samples under different dry densities.

also be due to the phenomenon of dilatancy in the highdensity model under low confining pressure.

\section{Conclusions}

Based on the laboratory consolidated-undrained triaxial compression experiment, PFC is used to conduct numerical tests on tailings with different dry densities, and the fish language is used to monitor the stress, strain, peak strength and coordi- nation number, particles velocity, and contact force between particles of the sample. Following conclusions are drawn:

(1) By comparing the laboratory test with the PFC triaxial compression simulation test, the stress-strain curve, peak strength, and elastic modulus of the numerical simulation of each dry density tailing sample under different confining pressures and the laboratory test are in good agreement 
(2) Compared with the case of high confining pressure, the numerical test at low confining pressure has a higher degree of coincidence with the laboratory triaxial compression test. This is due to the assumption that particles are rigid and incompressible in PFC. However, the greater the confining pressure, the greater the degree of particle crushing and deformation in laboratory test

(3) Under large confining pressure, the sliding and rotation of the particles inside the sample are restricted, suppressing the dilatancy of the sample

(4) The initial coordination number of the numerical model is large, which proves that the contact degree of the model is good to some extent

(5) In the triaxial numerical test, with the strain increases to a certain extent, the core area of the models bears most of the axial pressure

(6) Both macroscopic and mesoscopic studies have proved that due to the close arrangement of highdensity particles, the restraint force is small and the sample will tend to expand radially as loaded to a certain degree due to the slip and rotation between particles

\section{Data Availability}

The data that support the findings of this study are available from the corresponding author upon reasonable request.

\section{Conflicts of Interest}

The authors declare no conflicts of interest.

\section{Acknowledgments}

This work is supported by the National Natural Science Foundation of China (51774187 and 51804164); the Research Foundation of Education Bureau of Hunan Province (17A184); and the Natural Science Foundation of Hunan Province (2019JJ50498). Thanks to Hunan Province Engineering Technology Research Center for Disaster Prediction and Control on Mining Geotechnical Engineering (2019TP2070) for providing experimental platform support and thanks to the Central South University.

\section{References}

[1] Z. Song, H. Konietzky, and M. Herbst, "Bonded-particle model-based simulation of artificial rock subjected to cyclic loading," Acta Geotechnica, vol. 14, no. 4, pp. 955-971, 2019.

[2] Z. Song and H. Konietzky, "A particle-based numerical investigation on longwall top coal caving mining," Arabian Journal of Geosciences, vol. 12, no. 18, 2019.

[3] B. Dai, Y. Chen, G. Zhao, W. Liang, and H. Wu, "A numerical study on the crack development behavior of rocklike material containing two intersecting flaws," Mathematics, vol. 7, no. 12 , p. $1223,2019$.
[4] Z. Song, H. Konietzky, and M. Herbst, "Three-dimensional particle model based numerical simulation on multi-level compressive cyclic loading of concrete," Construction and Building Materials, vol. 225, pp. 661-677, 2019.

[5] Y. Y. Cui, J. H. Zhang, A. Tong, and N. Wu, "Automatic identification of discrete element meso parameters of sand materials," Mechanics and practice, vol. 41, no. 3, pp. 300-307, 2019.

[6] G. Y. Xu and Y. P. Sun, "Macro-microscopic parameter calibration for triaxial test of sand soil using iterative thought," Journal of Harbin Institute of Technology, vol. 49, no. 9, pp. 65-69, 2017.

[7] C. Liu, X. X. Cheng, W. Zhang, and B. Wang, "Research on the calibration process of parallel bonding mesoscopic parameters in PFC numerical simulation," Value engineering, vol. 36, no. 26, pp. 204-207, 2017.

[8] J. Yang and X. F. Han, "Correlation analysis of macromicroscopic parameters of rockfill material based on PFC," People's Yangtze River, vol. 49, no. 16, pp. 106-111, 2016.

[9] Y. F. Xu, "Simulation analysis of shear strength of coarsegrained soils based on particle breakage," Journal of Engineering Geology, vol. 26, no. 6, pp. 1409-1414, 2012.

[10] Y. Luo, X. N. Gong, and F. Liang, "Engineering mechanical properties of cohesionless soil simulated by threedimensional discrete particle unit," Journal of Geotechnical Engineering, vol. 30, no. 2, pp. 292-297, 2008.

[11] N. Li, "Transparent sand particle flow simulation of triaxial test," Geological society of China engineering geology professional committee, China geological survey, the hall of Qing Hai province, 2011 national engineering geological academic essays, Geological society of China engineering geology professional committee, the China geological survey, the hall of Qing Hai province: journal of engineering geology editorial office, vol. Supplement, no. 19, pp. 320-326, 2011.

[12] J. Zhou and Y. Chi, "Microscopic simulation of mechanical properties of sandy soil," Rock and Soil Mechanics, vol. 24, no. 6, pp. 901-906, 2003.

[13] Z. F. Shen, M. J. Jiang, F. Y. Zhu, and H. J. Hu, "Effects of discrete element microscopic parameters on macroscopic parameters of sand," Journal of northwest seismology, vol. 33, no. S1, pp. 160-165, 2011.

[14] X. T. Yin, Y. N. Zheng, and S. K. Ma, "Study on the internal scale ratio of geotechnical materials based on particle flow numerical test," Rock and Soil Mechanics, vol. 32, no. 4, pp. 1211-1215, 2011.

[15] S. Yang and X. Q. Li, "Direct shear simulation and macro microanalysis of sand based on PFC (3D)," Chinese journal of computational mechanics, vol. 36, no. 6, pp. 777-783, 2019.

[16] S. Yang and X. Q. Li, "Simulation of PFC (3D) sand soil with different particle shapes," Water conservancy and hydropower technology, vol. 50, no. 3, pp. 139-144, 2019.

[17] L. Geng, Z. Q. Huang, and Y. Miao, "Microsimulation of triaxial test of coarse grained soil," Journal of Civil Engineering and Management, vol. 28, no. 4, pp. 24-29, 2011.

[18] F. Wang, P. H. Xu, J. W. Gao, and B. Q. Lu, "Study on size effect of triaxial test of coarse grained soil based on PFC method," Highway engineering, vol. 39, no. 2, pp. 80-8380162, 2014.

[19] C. W. Yin, B. Ling, and L. G. Jiang, "Macroscopic and microscopic parameter analysis of sand based on particle flow method," Journal of coal, vol. 36, no. S2, pp. 264-267, 2011. 
[20] Y. H. Guo, Y. K. Tian, L. L. Wu et al., "Mechanical properties of tailings under different confining pressures under dry and wet cycling," Nonferrous metal engineering, vol. 10, no. 4, pp. 87-93, 2020.

[21] W. H. Liu, Q. Yang, X. W. Tang, and W. G. Li, "Mechanical properties of soils with different initial dry densities under dry-wet cycling conditions," Chinese journal of water resources, vol. 45, no. 3, pp. 261-268, 2014.

[22] X. L. Ning, Mesoscopic Triaxial Simulation and Microstructure Study of Clay Soils (Doctor's Degree Thesis), Zhejiang University, 2017.

[23] D. D. Shi, J. Zhou, M. C. Jia, and D. X. Yan, "Particle flow simulation of high stress one-dimensional compression characteristics of granular sand," Journal of Geotechnical Engineering, vol. 29, no. 5, pp. 736-742, 2007.

[24] M. J. Jiang, J. M. Konrad, and S. Leroueil, “An efficient technique for generating homogeneous specimens for DEM studies," Computers and Geotechnics, vol. 30, no. 7, pp. 579-597, 2003.

[25] C. Shi, Q. Zhang, and S. N. Wang, "Numerical simulation technology and application of particle flow (PFC5.0)," Rock and Soil Mechanics, vol. 39, no. S2, p. 36, 2018.

[26] T. Liu, B. Q. Lin, Q. L. Zhou, C. J. Zhu, and F. Z. Yan, "Mechanical behaviors and failure processes of precracked specimens under uniaxial compression: a perspective from microscopic displacement patterns," Tectonophysics International Journal of Geotectonics \& the Geology \& Physics of the Interior of the Earth, vol. 672, pp. 104-120, 2016. 